\title{
A Study Examining Change in Underrepresented Student Views of Engineering as a Result of Working with Engineers in the Elementary Classroom
}

\author{
Stephen Thompson and Jed Lyons \\ University of South Carolina \\ Columbia, SC 29208 \\ sthompson@sc.edu
}

\begin{abstract}
This paper describes the results of a National Science Foundation sponsored Graduate Teaching Fellows in K-12 Education project that was designed to increase elementary students' understanding of engineering, with an ultimate goal of increasing the probability of future involvement in engineering fields. This project, partnered graduate level engineering students called Engineering Fellows with grades 3, 4, and 5 urban classroom teachers. The Engineering Fellows worked for 20 hours a week over an entire academic year as a resource for the teachers, with 10 of those hours spent in various teaching roles. To capture student perceptions of engineers and engineering, a pre and post "Draw-an-Engineer" instrument was administered to one hundred and ninety project students. Pre and post interviews that focused on student drawings and student understanding of engineering were also completed with a subset of students. In this paper, project schools with a majority of underrepresented minority students are compared to project schools that did not contain a majority of underrepresented minority students. This comparison focuses on changes in student drawings and interview data over time amongst both groups. This comparison includes a discussion of both groups in terms of their developing understanding of engineering processes, engineering tools, and engineering fields represented by the generic term "engineering". Also included is a discussion of results in terms of implications for future policies and decision-making related to K-12 STEM education.
\end{abstract}

\section{Introduction}

Despite efforts to increase student interest in engineering-related fields, the number of U.S. citizens choosing engineering related careers is declining [1]. At the same time, the number of foreign nationals traditionally used to fill voids in U.S. engineering fields is also being restricted [1]. Concurrently, the number of underrepresented U.S. minorities (defined as students whose representation in a given field does not closely match their representation among the general population) obtaining degrees in science, technology, engineering or math (STEM) disciplines has changed little in the past twenty years [2]. This lack of participation in engineering, science and other technological fields by such a large segment of the U.S. population is an issue of critical importance, especially in light of minority population growth projections and our country's advancing reliance on technology. These issues arise at the same time that the importance of engineering related fields on national prosperity and security are becoming

Proceedings of the 2005 American Society for Engineering Education Annual Conference \& Exposition Copyright (C) 2005, American Society for Engineering Education 
increasingly evident [3]. This leads to a series of questions related to why U.S. citizens, especially underrepresented minorities, are not choosing engineering careers and what can be done to address the underlying issues that create this situation.

Many of the attitudes adults hold toward science and math are formed during elementary school and carried into adolescence and adulthood. Although elementary students' attitudes towards science and math are generally positive, their perceptions of scientists and engineers, and the work they do, are generally inaccurate [4]. Not only are these perceptions inaccurate, in the case of engineers, they are also generally less than favorable. For example, students ranked engineers eighth among 17 occupations in terms of prestige in a Harris poll [5]. These perceptions can influence students' selection of academic coursework throughout schooling, having a direct impact on student career opportunities [4]. The perceptions that are developed in elementary school then, result in fewer citizens selecting engineering careers.

The importance of student perceptions of engineering and related sciences is not lost on the educational community. A component of current K-16 education reform efforts in science, technology, engineering, and mathematics (STEM) is enhancement of student perceptions of the respective disciplines. Highlighted in these educational reform efforts is the need for engineers to take part in science and technological education at all levels $[6,7,8,9]$. Towards this end, several efforts have been attempted. These include the development of engineering-based curricula in primary and secondary education $[10,11,12]$, engineering workshops and short courses for teachers [13], and teacher-engineering graduate student teams co-developing lesson plans $[14,15]$ among others. Each of these approaches has the promise to influence students' understanding of engineering. At the same time these approaches lack a necessary component for promoting change in student perceptions of these fields: engineers engaging in extended collaborations with teachers in the school context $[9,16]$. This paper investigates a program that addresses this missing component, the Engineering Fellows Program, and reports changes in student perceptions of engineering as a result of program participation. Results from two groups of project schools are compared and contrasted. Project schools with a majority of underrepresented minority students are compared with project schools that did not contain a majority of underrepresented minority students. This comparison includes a discussion of both groups in terms of their developing understanding of engineering processes, engineering tools, and engineering fields represented by the generic term "engineering". The final part of the paper includes a discussion of results in terms of their implications for future policies and decisionmaking related to $\mathrm{K}-12$ STEM education.

\section{Program Description}

The Engineering Fellows Program is a part of the National Science Foundation's (NSF) Graduate Teaching Fellows in K-12 Education (GK-12) initiative [17]. In GK-12 projects, graduate students from STEM disciplines spend 20 hours a week serving as resources for K-12 science and math teachers over an entire academic year. This particular project paired graduate engineering and computer science students called Engineering Fellows (Fellows) with upper elementary science teachers. The collaborative pairs co-developed and co-taught student lessons focused on engineering examples, design approaches and problem solving techniques to show the application of science, technology and mathematics concepts. The Engineering Fellows Program operated on the premise that engineering makes science, technology and math concepts

Proceedings of the 2005 American Society for Engineering Education Annual Conference \& Exposition Copyright (C) 2005, American Society for Engineering Education 
relevant to the novice learner. At the same time, we believed this program would also positively influence students' perceptions of engineering.

\section{Methods}

A "Draw-an-Engineer" instrument was used to capture student perceptions of engineering [18]. The Draw an Engineer instrument was developed specifically for this project. It obtains its theoretical support from the extensive use of drawings by children to capture understandings and perceptions in many settings and fields that are otherwise difficult to ascertain $[19,20,21]$. One of the most well known of these instruments comes from the field of science, using students' drawings to reveal their perceptions of scientists and what it is they think scientists do [22, 23, $24,25]$. Similarly, the work reported in this paper compares young students' perceptions of the work engineers do to determine if there are differences in perceptions of engineering by racial group. In this way common perceptions about engineering can be identified and differences determined so that misconceptions and stereotypes about engineering as a career may begin to be addressed for all groups of students.

\section{Participants}

Twelve Engineering Fellows worked in collaborative pairings with 12 elementary teachers at 4 school sites to co-developed and co-teach science lessons to students in grades 3-5. Each Fellow worked with a single teacher for a semester and then rotated to another teachers' classroom, with each of the twelve teachers working with two Fellows consecutively over the course of an entire academic year. All 4 of the project schools were located in urban school districts. The schools represented a diverse student population. Two of the schools had large numbers of underrepresented minority students (above 80\% African-American at each site), while the other schools had significantly lower percentages of underrepresented minority students (above $80 \%$ Caucasian at each site).

\section{Design and Procedures}

At the beginning of the first semester of the Fellow's work in schools, students were asked to draw a picture of an engineer working, i.e., "Draw-an-Engineer". A subset of 8 randomly selected students' from two sites that represented the widest spectrum of diversity participated in follow-up, semi-structured interviews. These interviews were intended to provide students with an opportunity to explain their drawings and provide researchers with information about their interpretations of the drawings to determine the accuracy of their interpretations. After having a Fellow in the classroom for an academic year, the students were again asked to complete the Draw an Engineer activity and the same subset participated in follow-up interviews related to their drawings.

Analysis

Initial analysis of student drawings was completed using the Draw-an-Engineer Checklist (Checklist) [18]. To create this Checklist, the Fellows and their engineering professors completed the Draw an Engineer activity. The categories included in the Checklist were developed based on these drawings and the feedback the Fellows and their professors provided.

Drawings were examined and artifacts related to the following four thematic groups were counted: "Tools or Equipment," "Diversity of Fields," "Process," and "Design". Points were

Proceedings of the 2005 American Society for Engineering Education Annual Conference \& Exposition Copyright (C) 2005, American Society for Engineering Education 
allocated based on the number of drawing artifacts that could be placed within the category criteria outlined below. The sum of all four items (maximum possible score 8) was then used as an initial assessment of students' perceptions of engineering.

- Tools or Equipments: Each hammer, screwdriver, ruler, computer, or other tool that might be used in engineering was counted. One point was given for one object, two points for two to three objects, and a maximum of three points for four or more objects.

- Diversity of Fields: Relevant objects or products such as electric lines, bridges, chemical vials, or rockets that characterized different fields of engineering were counted. One point was given to objects that represented a single field, two points were given when two objects that represented different fields were found, and three points were given when three objects were found that represented three fields.

- Process: This item was included to give credit to those drawings that not only included products, but also portrayed the working processes that lead to the creation of products such as constructing models, conducting chemical analysis or manufacturing products.

- Design: This item was included to give additional credit to those drawings that included mathematical symbols, formulae, or graphical representations that captured aspects of engineering design processes.

To determine themes that were apparent across student drawings but not captured by the Checklist, additional open-ended analysis of student drawings was conducted. This method allowed for further development of the categories reported in this paper. It was also a form of analysis that followed the data rather than preceding them, allowing the richness in the student drawings to emerge. Interview data were also analyzed in a similar manner to determine the accuracy of the raters' interpretations of student drawings using the Checklist instrument. This analysis in total led to the findings described below, which also encompass findings from the Checklist.

\section{Scoring}

Following a training session, two research assistants from the College of Education scored a total 191 pairs of pre-and post-drawings using the Checklist. The inter-rater reliability estimate for the pre-drawings was 0.93 while the post-drawings reliability estimate was 0.87 . The author completed additional open-ended analyses using naturalistic methods that focused on identifying emerging themes in student drawings.

\section{Results}

Overall, students better understood engineering as a result of working with a Fellow. The first evidence of this is displayed in students' scores on the Checklist, which increased across all categories (See Table 1). The rise in scores indicates a general improvement in student understanding of engineering amongst all project students as reflected by the Checklist criteria. In addition to raw score increases, the post-drawing mean score for all categories combined, 2.45 $(\mathrm{SD}=1.43)$, was considerably higher than the pre-drawing mean for the same categories, 1.88 $(\mathrm{SD}=1.63)$. A dependent $\mathrm{t}$-test with a $95 \%$ confidence interval showed this difference to be statistically significant.

Proceedings of the 2005 American Society for Engineering Education Annual Conference \& Exposition Copyright (C) 2005, American Society for Engineering Education 
Table 1. Individual Draw an Engineer Checklist Item Scores.

\begin{tabular}{|l|c|c|c|c|c|}
\hline \multirow{2}{*}{ Engineering Criteria } & \multirow{2}{*}{ Score } & \multicolumn{2}{|c|}{ Pre Drawings } & \multicolumn{2}{c|}{ Post Drawings } \\
\cline { 3 - 6 } & 0 & $\mathrm{~N}$ & $\mathrm{P}$ & $\mathrm{N}$ & $\mathrm{P}$ \\
\hline Tools or Equipment & 1 & 59 & 51.8 & 65 & 37.7 \\
\hline & 2 & 23 & 28.3 & 36 & 34.0 \\
\hline & 3 & 15 & 7.1 & 18 & 9.9 \\
\hline & & & & & 103 \\
\hline Process & 0 & 122 & 63.9 & 88 & 53.9 \\
\hline & 1 & 69 & 36.1 & & 46.1 \\
\hline & & & & 179 & 93.7 \\
\hline Design/Symbols & 0 & 185 & 96.9 & 11 & 5.8 \\
\hline & 1 & 6 & 3.1 & & 0.005 \\
\hline & 2 & 0 & 0.0 & 20 & 10.5 \\
\hline & & & & 160 & 83.8 \\
\hline Fields & 0 & 57 & 29.8 & 9 & 4.7 \\
\hline & 1 & 124 & 65.0 & 2 & 1.0 \\
\hline
\end{tabular}

Note. $N=$ The frequency count of characteristics in a drawing. $P=$ The percentage of the total number of characteristics in a drawing.

Student scores were then broken into subgroups for further analysis. The first group, titled Underrepresented, consisted of students from project schools with above 80 percent of underrepresented minority students as previously defined. The second group, titled Control, consisted of students from project schools with below 20 percent of underrepresented students. Mean differences for both groups were determined across all categories. Dependent t-tests with a 95\% confidence interval showed total as well as differences between groups across all categories to be statistically insignificant (See Table 2).

Table 2. Mean Differences Between Pre- and Post-Drawings' Characteristics and Totals for Underrepresented and Control Schools.

\begin{tabular}{|l|c|c|c|c|c|c|}
\hline & & & \multicolumn{2}{|c|}{ 95\% Confidence Interval } & & \\
\hline & Mean & SE & Lower & Upper & $\mathrm{t}$ & Sig \\
\hline Tools or Equipment & .05 & .16 & .36 & .27 & .307 & .453 \\
\hline & & & & & & \\
\hline Process & .07 & .89 & .24 & .11 & .783 & .570 \\
\hline & & & & & & \\
\hline Designs/Symbols & .03 & .04 & .05 & .10 & 1.52 & .131 \\
\hline & & & & & & \\
\hline Fields & .06 & .09 & .23 & .11 & .701 & .953 \\
\hline & & & & & & \\
\hline Total & .17 & .27 & .70 & .36 & .641 & .803 \\
\hline
\end{tabular}

Note. Mean $=$ mean differences between school groups. SE $=$ Standard error. $t=$ The calculated t statistic. Sig. = Significance level.

Proceedings of the 2005 American Society for Engineering Education Annual Conference \& Exposition Copyright (C) 2005, American Society for Engineering Education 
Based on these findings it was determined that there were no statistical differences in the changes in students' scores as reflected by the Checklist categories. However, earlier work on student perceptions of engineering revealed interesting changes in student perceptions of engineering through open-ended analysis that weren't captured by the Checklist instrument [26]. Based on this information, additional qualitative analysis of student drawings was conducted and is described below.

\section{Tools or Equipment}

Using the Draw an Engineer Checklist, an increase in the number of tools and equipment depicted in student drawings of engineers was found. The post-drawing mean for the Tools or Equipment category, $0.9974(\mathrm{SD}=0.908)$ was found to be considerably higher than the predrawing mean, $0.7539(\mathrm{SD}=0.904)$. A dependent t-test with a $95 \%$ confidence interval showed this difference to be statistically significant. However, as stated previously, differences between the Underrepresented and Control groups were found to be insignificant (See Table 2). In spite of this, additional open-ended analysis identified several patterns in student depictions of engineering tools and the ways engineers were being depicted using them across groups that are described below.

Initial student portrayals among both groups focused mainly on construction tools and their use in engineering. For example, the largest cluster of student pictures within this category, 84 drawings (See Figure 1), included tools used to build, fix or repair objects (hammers, screwdrivers, etc.).

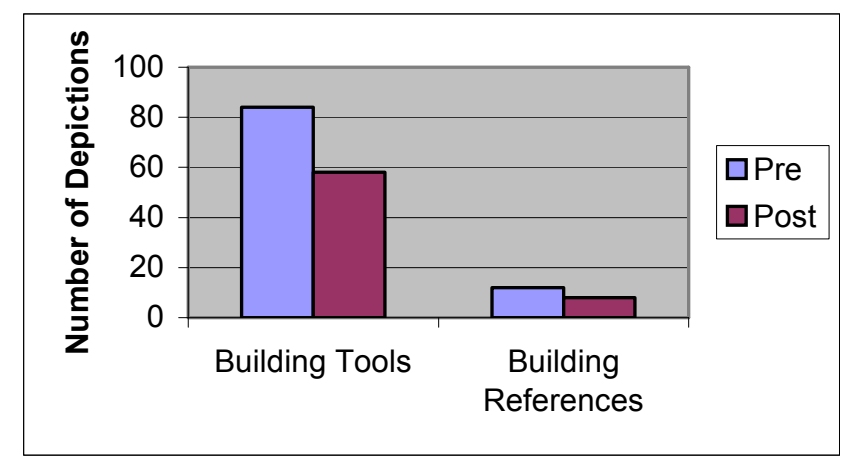

Figure 1. Engineering tools

These pre-drawings generally portrayed engineers engaged in physical processes associated with constructing or fixing structures (mainly buildings and bridges) and cars. When captions were included they frequently used the words "fixing" or "building" to describe the action that was occurring. Twelve of these drawings ( $6.2 \%$ of all pre-drawings) also included a specific reference to building when describing the action that was occurring.

On post-drawings there was less of an emphasis on hand tools used in engineering across both groups with only 58 student drawings including tools used to build, fix or repair objects.

Twenty-six of these post-drawings came from the Underrepresented group (representing 27.65\% of the total Underrepresented group post-drawings) while 32 of these post-drawings came from the Control group (representing $32.98 \%$ of the total Control group post-drawings). When captions were included the number of explicit references to building reduced to only 8 across both groups ( 5 from the Underrepresented group and 3 from the Control group). These

Proceedings of the 2005 American Society for Engineering Education Annual Conference \& Exposition Copyright (C) 2005, American Society for Engineering Education 
reductions represented a substantial decrease in the percentage of students who referenced building as an aspect of engineering across both groups (3.2\% of all post-drawings).

Collectively, the evidence discussed to this point was seen as an indication that both groups of students were less likely to perceive engineering work as involving the physical action that would be associated with constructing.

At the same time that fewer students were focusing on building in their drawings, more students were including tools that captured the mental aspects of engineering such as designing or modeling. This shift became apparent when student drawings of computers were examined (see Figure 2).

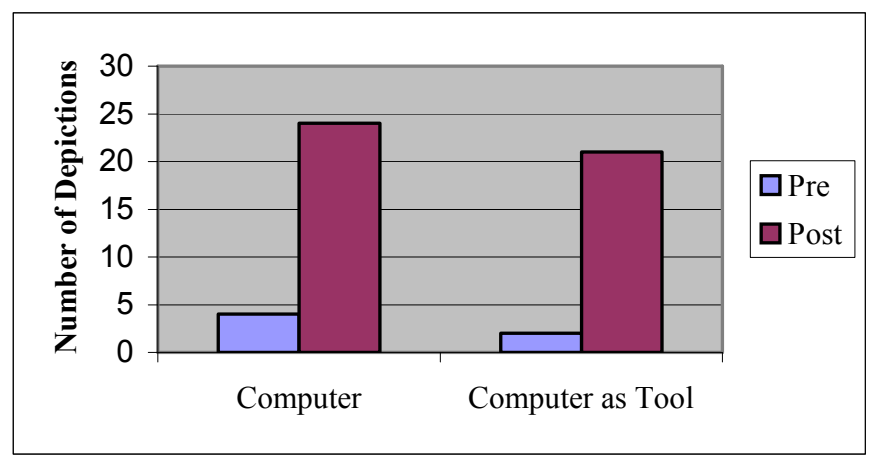

Figure 2. Computer depictions

For example, student pre-drawings included only four pictures of computers. Of these four drawings, one displayed a computer unoccupied, one showed an engineer fixing a computer, and two showed engineers sitting at computers doing "work". Student post-drawings, on the other hand, included twenty-four depictions of computers. More important than the actual number of computers drawn though were the ways that students depicted computers being used by engineers. Twenty-one student post-drawings included engineers using computers as tools in their work. This jump in the number of engineers using a computer was seen as an important indicator of developing student understanding of engineering work. Further, of the twenty-one post-drawings that depicted engineers using computers, six showed engineers using the computer in some aspect of modeling and/or designing.

Initially, these findings were thought to indicate a phenomenon that occurred across multiple sites. However, of the twenty-four depictions of computers identified, it was discovered that twenty-one of them came from the Underrepresented group. Further examination showed that seventeen of the twenty-one came from students in one teacher's classroom. Upon examination of collaborative pairings of teachers and Fellows it was discovered that the students in this teacher's classroom were highly involved in integrating technology across the curriculum and also worked with a Fellow who was majoring in computer science. Both of these factors were believed to have an impact on students' perceptions of the ways that engineers use computers in their work.

These results show students' post-drawings focused less on tools used to construct buildings, bridges and cars. They also show fewer students referenced building when describing what the engineers were doing. Both of these changes were found across all groups of student.

Proceedings of the 2005 American Society for Engineering Education Annual Conference \& Exposition Copyright (C) 2005, American Society for Engineering Education 
Additional findings highlighted a significant change in student depictions of computers, but this occurred within only one subgroup of students. This classroom and the students in it were uniquely positioned to take advantage of this collaboration. The students were using resources and instructional materials with which the Fellow was uniquely qualified. Prior research on these types of collaborations indicates that GK-12 Fellows often experience a severe learning curve in terms of resources and materials needed to teach a subject area with which they are not familiar [27]. This finding lends support to the notion that the most effective scientist/engineerteacher collaborations are those in which subject-matter expertise is carefully matched to the teachers' curriculum.

In addition to a greater number of tools being identified on student post-drawings, those that were identified also represented a wider array of engineering fields. This interpretation is consistent with, and supported by, the findings discussed in the following section.

\section{Diversity of Fields}

At the end of this experience both groups of students displayed a more complete understanding of the diversity of fields represented by the generic term, "engineering". Analysis of student drawings using the Checklist showed that the post-drawing mean for the category Diversity of Fields, $0.9503(\mathrm{SD}=0.371)$ was higher than the pre-drawing mean, $0.7696(\mathrm{SD}=0.579)$. A dependent t-test with a $95 \%$ confidence interval showed that this difference was statistically significant. The number of students depicting at least one field of engineering on post-drawings then was significantly higher than the number of similar pre-drawing depictions. As occurred earlier, additional analysis showed that the difference in mean score changes between groups was statistically insignificant (see table 2).

Across both groups, student post-drawings included more objects representative of a wider array of engineering fields. Post-drawings also included considerably more explicit references to fields of engineering. For example, on student pre-drawings only one explicit reference to a field of engineering (Computer) was found. This contrasts with fourteen explicit references referring to five different fields of engineering (Computer, Electrical, Chemical, Civil, and Mechanical) identified on student post-drawings. Nine of these references were found on Control group drawings, while five were found on Underrepresented group drawings. Some of the postdrawing references gave a simple descriptive title accompanying a drawing. Other student drawings provided both a descriptive title and an explanation of the picture such as, "A Civil Engineer making a highway."

A key feature of post-drawings that included explicit references was student ability to accurately portray the objects associated with the fields referenced. Thirteen of the drawings depicted objects that would be associated with engineers working in these fields. For example, the drawing of the Civil Engineer discussed above shows an engineer with objects consistent with the field of Civil Engineering (e.g., road, road building equipment, etc.). Nine of the postdrawings with explicit references came from the Control group and four from the Underrepresented group. Further, eleven of the thirteen drawings accurately depicted engineers engaged in activities that were consistent with the work normally completed within the stated fields. For instance, one of these drawing shows two Civil Engineers looking at a blueprint of a bridge. The blueprint can be seen and depicts the bridge that is behind the engineers. Eight of 
these types of depictions came from the Control group and three from the Underrepresented group. This combination of data supports three key conclusions. First, students better understood the diversity of fields represented by the term engineering as a result of this project. Second, students better understood the work typically done within the fields referenced after working with a Fellow for a year. Third, there was little difference in changes in student perceptions based on minority-status.

\section{Engineering as a Process}

In addition to enhancing student understanding that engineering encompasses multiple fields, student post-drawings also portrayed more engineers engaged in engineering processes. Using the Draw an Engineer Checklist the post-drawing mean for the category Process, $0.4607(\mathrm{SD}=$ 0.447 ) was higher than the pre-drawing mean, $0.3586(\mathrm{SD}=0.442)$. This difference was found to be statistically significant. These findings demonstrate that at the end of this experience significantly more students depicted engineering processes. Again, the differences between the Control and Underrepresented groups were found to be insignificant (see Table 2). Further examination of the ways that students were defining engineering processes revealed additional patterns that highlighted changing student understanding of engineering.

In the previous section the idea that fewer building tools were found on students' post-drawings was discussed. Just as fewer building tools were depicted, fewer post-drawings depicted engineers engaged in building processes. Conversely, more post-drawings depicted engineers engaging in mental processes related to engineering such as designing or modeling. Other process depictions that increased pre to post focused on product realization. For example, eight post-drawings featured engineers "making" things with captions that included variations of the words create or invent to describe the engineering action. Three of these came from the Control group and five came from the Underrepresented group. No such captions were found on student pre-drawings.

In addition, students also developed an understanding of the importance of communicating ideas as a process of engineering. On student pre-drawings only two student drawings depicted an engineer presenting or teaching information to others. On post-drawings, fourteen students drew pictures that could be identified as engineers presenting or teaching information to others. These were evenly divided between the Underrepresented and Control groups. Six of these showed engineers presenting information to others in formal settings. The eight others showed engineers in the field sharing information with other engineer-like characters. These findings, in combination with those described above, indicted that students were developing a clearer understanding of processes associated with engineering.

In addition to the findings related to processes described above, analysis of student depictions showed substantial gains in student understanding of designing as an engineering process. A discussion of this interpretation is included below.

\section{Design}

Using the Draw an Engineer Checklist, the post-drawing mean for Design, $0.0605(\mathrm{SD}=0.219)$ was higher than the pre-drawing mean, $0.0316(\mathrm{SD}=0.167)$. A dependent t-test with a 95\% confidence interval demonstrated that the pre to post increase of mathematical symbols, 
formulae, and graphical representations that captured aspects of engineering design processes was not significant. Further analysis showed no statistical difference between the Control and Underrepresented student depictions within this category (see table 2). Even though these differences were not statistically significant, open-ended analysis showed substantial gains in student understanding of designing and its relationship to engineering.

Analysis of pre-drawings showed only a few students made the connection between engineering and designing. For example, eight pre-drawings portrayed engineers engaged in designing processes (see Figure 3). Of these eight drawings only two explicitly referenced designing as an aspect of engineering work. The other six pre-drawings depicted some aspect of the design process occurring (engineers using a blueprint or model as a guide) or provided an explanation that was related to design processes such as, "An engineer is someone who develops stuff."

On the other hand, post-drawing portrayals of designing as an aspect of engineering increased substantially. For example, twenty-nine post-drawing depictions of engineers engaged in aspects of designing or working with design artifacts were found. Eleven of these came from the Control group while eighteen came from the Underrepresented group.

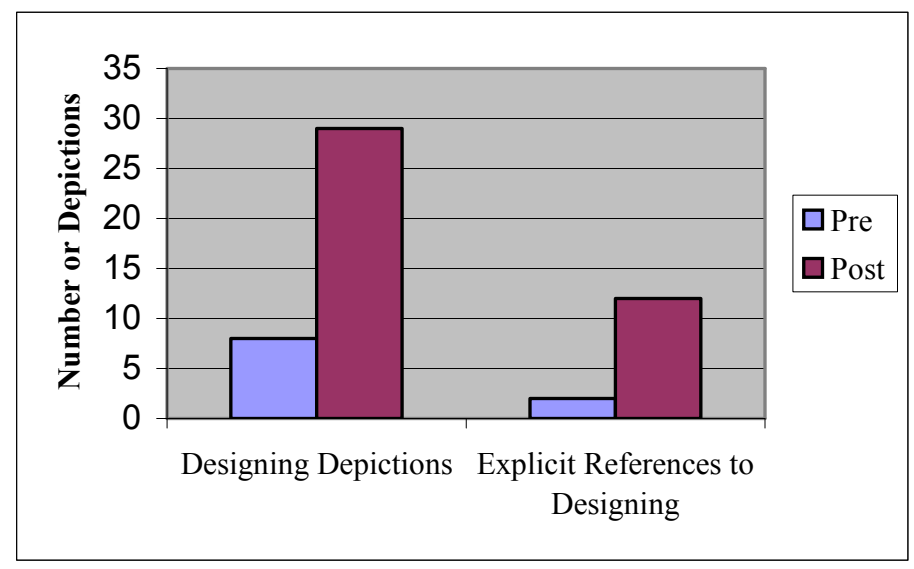

Figure 3. Portrayals of designing

Twelve included an explicit reference to designing in the caption provided such as, "This is a Mechanical Engineer designing a car." Eight of these came from the Control group while four came from the Underrepresented group. Other significant captions and depictions that were somewhat evenly spread across the Control and Underrepresented groups were also noted. For example, five post-drawings included a caption such as, "The engineer is drawing and designing a bridge", and depicted engineers engaged in drawing and/or designing. Six others showed engineers with design artifacts with less explicit captions such as, "Two men fixing and planning the car." Further, eight of the post-drawings included blueprints of some type being used by the engineers. Finally, four depicted engineers engaged in "problem solving" processes related to designing such as a drawing of an engineer studying a blueprint with the caption, "To make this better we need to...." These increases in references to and portrayals of designing, including the increased student portrayals of computers as design tools discussed previously, were seen as evidence that students were developing a better understanding of engineering processes. Further, the analysis discussed to this point indicated that students were moving away from the perception

Proceedings of the 2005 American Society for Engineering Education Annual Conference \& Exposition Copyright (C) 2005, American Society for Engineering Education 
that an engineer is a builder and towards a more accurate perception that an engineer is a creator or designer. These changes occurred across both groups of students, but in different forms. The nature of the change in perceptions seemed to be influenced by the context of the classroom and the background of the Fellow. For example, students in the technology-rich classroom with the computer science Fellow depicted the greatest number of engineers using computers as design tools.

\section{Misconception Reduction}

In addition to positive changes in student understanding of engineering, fewer misconceptions of engineering were encountered on students' drawings, pre to post. This can be seen in the reduced number of students who completed the Draw an Engineer activity by choosing the "I don't know" option and in the reduced number of students who drew train conductors for their engineers. On pre-drawings, 53 students wrote some variation of "I don't know" when asked to draw an engineer (see Figure 4). Additionally, on student pre-drawings twenty-six students drew pictures of a train conductor (engineer) for their "engineer at work". The majority of these drawings showed the engineer as the person who drives the train. Although a person who drives a train is called an engineer, one of the intents of this project was to help students understand that this is not the type of engineering typically done by engineering students graduating from institutes of higher education. Together these two groups represented $41 \%$ of the preintervention responses provided by students and were evenly distributed across both groups of student's pre-drawings.

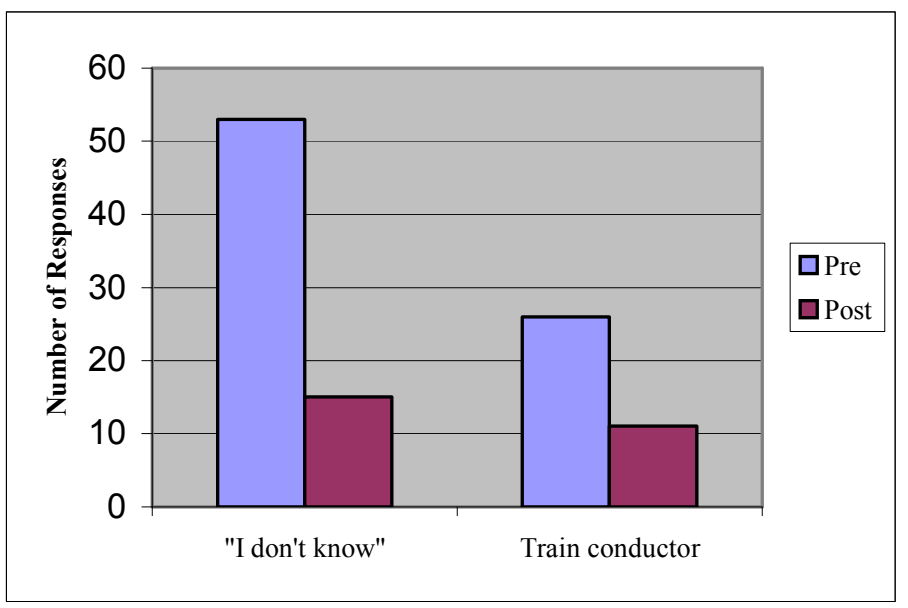

Figure 4. Engineering misconceptions

On post-drawings only fifteen students elected to respond with, "I don't know" when asked to draw an engineer. Ten of these came from the Control group and five from the Underrepresented group. Additionally, only eleven post-drawings depicted an engineer as a person who drives a train. Seven of these came from the Control group while four came from the Underrepresented group. Together these two sets of depictions represented only $13.6 \%$ of the total post-intervention responses provided by students. Both of these reductions were seen as further evidence that both groups of students gained a more accurate understanding of engineering as a result of working with a Fellow. 


\section{Summary}

As a result of working with a Fellow for a year, both groups of elementary students developed clearer perceptions of engineers and engineering. This can be seen in students' depictions of engineering tools, their representations of engineering fields and their portrayals of engineering processes. Analysis of student portrayals of engineering tools demonstrated that students were moving away from the notion that an engineer is a builder and towards a more accurate perception that an engineer is a designer. Student depictions also showed that they better understood the diversity of fields represented by the term engineering and better understood the work typically done within engineering fields. Further, analysis of student drawings highlighted developing student understanding of engineering processes and designing as an aspect of engineering. In addition to positive changes in depictions of engineering, students held fewer misconceptions related to engineering. Reductions in student misconceptions of engineers and engineering were seen as further evidence that students developed more accurate perceptions of both as a result of program participation.

Although similar results were found across both groups of students, differences in developing student perceptions of engineers were also identified. Those students who worked with an engineer, in a field within which the Fellow was highly qualified and knowledgeable of the resources and instructional materials, gained clearer perceptions of the discipline and it's relationship to engineer. Project students who worked in a technology rich environment with a graduate-level computer science engineering Fellow demonstrated significant gains in their understanding of computer use in engineering, especially in terms of the ways that computers are used as engineering tools. These findings lend support to the idea that these types of collaborations are most successful when the Fellow's expertise is closely matched to the teacher's curriculum.

These findings have significance for policy-makers, educators, engineers and issues of national security. There is a clearly documented need to increase participation, especially underrepresented minority participation, in engineering sciences and related fields. Policymakers have been searching for viable solutions to increase this participation for some time. At the same time the creation of a scientifically educated and aware public is necessary in order to guide the adoption, and debate the societal implications, of new sciences and technologies. The first steps to increasing participation in, and developing a greater understanding of, engineering and related sciences is to inform K-12 students about what engineering sciences actually entail and to reduce misconceptions related to these fields. The Engineering Fellows Program demonstrates the potential to be a first step towards addressing both of these critical needs.

Additionally, the idea that GK-12 programs can effectively alter student perceptions of a discipline is supported by these findings, when the right conditions are met. First, this project highlights the need for these collaborations to be extended, in the school context, and focused on the teacher's curriculum. Second, the importance of a "match" between Fellow expertise and teacher curriculum is highlighted in these findings related to students' perceptions of computer use in engineering. 


\section{Acknowledgement}

This material is based upon work supported by the National Science Foundation's Graduate Teaching Fellows in K-12 Education Program under Grant No. 0086427 and by the South Carolina Commission on Higher Education's Centers of Excellence Program. Any opinions, findings, and conclusions or recommendations expressed in this material are those of the authors.

\section{References}

1. National Science Board. 2004. Science and Engineering Indictors 2004. Available on-line at $<$ Retrieved August 10, 2004 from http://www.nsf.gov/sbe/srs/seind04/>.

2. National Science Foundation. (1996). Women, minorities, and persons with disabilities in science and engineering: 1996, (Report No. NSF 96-311). Arlington, VA: Author. (ERIC Document Reproduction Number ED 402 192).

3. National Science and Technology Council from the White House. 2000. Ensuring a strong U.S. scientific, technical, and engineering workforce in the 21 st Century. Available on-line at < http://www.whitehouse.gov/media/pdf/workforcerpt.pdf $>$.

4. National Science Board. 2002. Science and Engineering Indictors 2002. Available on-line at $<$ Retrieved July 23, 2004 from http://www.nsf.gov/sbe/srs/seind02/start.htm.

5. Taylor, H. 2000. Doctors Seen as Most Prestigious of Seventeen Professions and Occupations, Followed by Scientists (\#2), Teachers (\#3), Ministers/Clergy (\#4) and Military Officers (\#5). Harris Interactive. The Harris Poll. Available at $<$ http://www.louisharris.com/harris_poll/index.asp?PID $=111>$.

6. International Society for Technology in Education. 2002. National Educational Technology Standards for Teachers: Preparing Teachers to Use Technology. Eugene, OR, author.

7. National Research Council. 2000. Inquiry and the National Science Education Standards. Washington DC, National Academy Press.

8. National Research Council. 1996. The Role of Scientists in the Professional Development of Science Teachers. Washington, National Academy Press.

9. National Research Council. 1996. National Science Education Standards. Washington, National Academy Press.

10. Carlson, L. and J.F. Sullivan. 2004. Exploiting Design to Inspire Interest in Engineering across the K-16 Engineering Curriculum, International Journal of Engineering Education, 20/8, 372-378.

11. Verner, I. M. and D.J. Ahlgren. 1997. Fire-Fighting Robot Contest: Interdisciplinary Design Curricula in College and High School. Journal of Engineering Education, 91/3, 355-359

12. Carroll, D. R. 1997. Bridge Engineering for the Elementary Grades. Journal of Engineering Education, 86/3. 221-226.

13. Poole, S. J., J.L. deGrazia, and J.F. Sullivan. 2001. Assessing K-12 Pre-Engineering Outreach Programs. Journal of Engineering Education, 90/1, 43-48.

14. Neubert, J. J., C.G. Widstrand, A.M. Pumper, B. Swanson, and A.B. Ellis. 2001. Integrating Materials Science into the High School Chemistry Curriculum, Proceedings of the 2001 American Society for Engineering Education Annual Conference \& Exposition, June 24 - 27, 2001, Albuquerque, New Mexico.

15. Mooney, M. A. and T.A. Laubach. 2002. Adventure engineering: A design centered, inquiry based approach to middle grade science and mathematics education. Journal of Engineering Education, 91/4, 309-318. 
16. National Academy of Sciences. 1998. Agriculture's Role in K-12 Education: Proceedings of a Forum on the National Science Education Standards. Washington, National Academy Press.

17. National Science Foundation. 2004. Graduate Teaching Fellows in K-12 Education. Available on-line at $<\underline{\text { http://www.ehr.nsf.gov/dge/programs/gk12/>. }}$.

18. Yap, C.C., C. Ebert, and J. Lyons. 2003. Assessing students' perceptions of the engineering profession. Proceedings, 2003 South Carolina Educators for the Practical Use of Research Annual Conference. Columbia, South Carolina.

19. Cohen, O. 1999. Young children's adjustment to their parent's divorce as reflected by their drawings. Journal of Divorce and Remarriage, 30(1-2): 47-70.

20. Fetherston, T. 1999. Draw a computer user. Paper presented at Australian Association for Research in Education 1999 conference. Available on-line at http://www.aare.edu.au/99pap/fet99592.htm.

21. Fournier, J. E. and S.S. Wineburg. 1997. Picturing the past: Gender differences in the depiction of historical figures. American Journal of Education, 105(2), 160-185.

22. Chambers, D.W. 1983. Stereotype images of the scientist: The draw-a-scientists test. Science Education, 67(2), 255-265.

23. Huber, R.A. and G.A. Burton. 1995. What do students think scientist look like? School Science and Mathematics, 95(7), 371-376.

24. Matthew, B. 1996. Drawing scientists. Gender and Education, 8(12), 231-243.

25. Sumrall, W. J. 1995. Reasons for perceived images of scientists by race and gender of students in grades 1-7. School Science and Mathematics, 95(2), 83-90.

26. Thompson, S. and Lyons, J. 2004. Elementary students' perceptions of engineering: Why should engineers care what kids think? Journal of Engineering Education (JEE-2004-4165), submitted December 2004, accepted for review.

27. Thompson, S., Collins, A., Metzgar, V., Joeston, M., Shepherd, V. 2002. Exploring graduatelevel scientists participation in a sustained k-12 teaching collaboration. School Science and Mathematics, 102(6), 254-265.

\footnotetext{
Biographical Information

Dr. Thompson is an Assistant Professor of Elementary Education at the University of South Carolina and the Research Director of the South Carolina Center for Engineering and Computing Education. He teaches courses in science education and classroom instructional technology. His research interests include Engineering Education K16, collaborations between university-based STEM personnel and K-12 teachers, and inquiry-based instruction.
}

Dr. Lyons is an Associate Professor of Mechanical Engineering at the University of South Carolina and the Director of the South Carolina Center for Engineering and Computing Education. He teaches laboratories, design, and materials science to undergraduates, graduate students and K-12 teachers. He researches engineering education, plastics and composites. He is the principal investigator for the GK-12 program. 